\title{
Comparative Study on RAOs of a Ship under Transient Gaussian Wave Packets by Marginal Hilbert Spectrum and Fourier Spectrum
}

\author{
Zhen Liu, Sheming Fan \\ Shanghai Key Laboratory of Ship Engineering, \\ Marine Design and Research Institute of China, \\ Shanghai, 200011, China
}

\author{
Longbin Tao \\ Department of Naval Architecture, Ocean and \\ Marine Engineering, University of Strathclyde, \\ Glasgow G40LZ, United Kingdom
}

\begin{abstract}
Sea-keeping model tests of ships based on transient waves have been widely applied over the past several decades. In order to obtain response amplitude operators (RAOs) of a ship, most of the post-processing of the experimental data uses the fast Fourier transform (FFT) to obtain the wave spectrum and the corresponding response spectrum. However, for transient waves related model tests, FFT may produce larger errors due to its characteristics. Hilbert-Huang transform (HHT) is a newly developed signal analysis tool which is suitable for nonlinear and non-stationary data. The application of HHT to the post-processing of the experimental data of sea-keeping model tests of ships has not yet been investigated. In this study, the transient wave packets satisfying a Gaussian wave spectrum were generated in a large towing tank to conduct the sea-keeping model tests of a drilling ship under the condition of head waves, oblique waves and beam waves, respectively. Then the marginal Hilbert spectrum (MHS) in the framework of HHT is introduced to obtain the motion and the acceleration RAOs the drilling ship. In order to demonstrate the effectiveness of the approach, the results based on FFT and regular waves are also presented. It is found that in most cases, in comparison to that by means of FFT, the RAOs of the ship based on the transient Gaussian wave packets by means of MHS agree better with the results based on regular waves, especially for roll motion with significant nonlinear
\end{abstract}

characteristics. Due to the advantages of HHT, the MHS approach employed in this study is expected to play a vital role in more sea-keeping related model tests of ships.

Keywords: Marginal Hilbert spectrum; Transient Gaussian wave packet; RAO; sea-keeping model test.

\section{INTRODUCTION}

In sea-keeping model tests of ships, regular waves or white-noise irregular waves are frequently used to obtain response amplitude operators (RAOs) of motion as well as acceleration. A series of regular wave tests is time-consuming (about $60 \mathrm{~min}$ ) and not easy to capture the peaks of a RAO curve. A whitenoise test holds short duration (10 30 min), but may encounter the effects of wave reflection produced by tank walls. The sea-keeping model tests by means of transient waves (focused wave groups) have rather short duration (1 2 min) and can thus improve significantly the test efficiency. Moreover, the tank wall effects can also be avoided effectively by using transient waves. Therefore, it is of primary significance to carry out studies on sea-keeping model tests of ships by transient waves.

Over the past several decades, many studies have been reported on simulation of transient waves and related model tests of ships. Davis and Zarnick (1964) first proposed a method for transient wave simulation. They generated a train of waves with increasing wavelength by linear sweeping frequency 
technology. Then the waves developed transient wave packets by focusing at a specific location. As the effect of the transfer function of the wave generator was not taken into account, it was difficult to control the profile of the wave train and the corresponding spectrum. By introducing the transfer function of a wave generator, Takezawa and Hirayama (1976) improved the above-mentioned method and obtained transient waves with a good spectral profile. It was pointed out that the wave profile of transient waves still needs to be improved. Clauss and Bergmann (1986) derived the analytical expression of a transient wave packet based on a Gaussian wave spectrum (amplitude-wave number spectrum), which involves the maximum wave amplitude of the wave packet at the focusing location. It was indicated that the simulated transient wave packets based on the analytical expression can exhibit a good wave profile and spectral characteristics. It was also shown that the heave and pitch RAOs of a ship with different forward speeds by means of the transient wave packets are in good agreement with those by regular waves. It is noticed that, however, the derived analytical expression cannot immediately reflect the influence of significant wave height. Using a Gaussian wave spectrum with significant wave height, Zhao et al. (2017) simulated focused wave groups in a moderate sea state and conducted associated studies on gap resonance issues. As they employed the "NewWave" theory, it was easy to simulate transient waves with specified focused wave amplitude.

Although it is convenient to control the spectral width of a Gaussian wave spectrum by adjusting its shape factor, for some model tests wave spectra with larger widths may be required. Using a wave spectrum similar to white noise, Grigoropoulos et al. (1994) simulated transient focused wave groups considering measured phase differences induced by wave propagation and conducted the corresponding sea-keeping model tests of a ship. It was found that the heave and pitch RAOs of a ship by means of the transient wave groups are in satisfactory agreement with those based on regular waves. It is also noted that the model tests by means of transient waves may suffer nonlinear effects from the focused wave. In order to eliminate the nonlinear effects, Reilhac et al. (2011) applied transient waves focused by wave crest and wave trough respectively to conduct sea-keeping model tests of a ship. It was found that the surge, heave and pitch RAOs by means of the approach agree well with those by means of regular waves and irregular waves. However, the influence of the change in the focused wave amplitude was not illustrated in their study.

Most of the aforementioned studies employed transient waves with smaller focused wave amplitudes. Whether transient waves with larger focused wave amplitudes are suitable or have any effects on the RAOs obtained based on the corresponding model tests have not been studied in detail. In addition, little literature reported seakeeping model tests of a drilling ship with a moon pool under transient focused waves. On the other hand, the traditional practice in post-processing for obtaining the RAOs based on transient waves related model tests makes use of fast Fourier transform (FFT) to obtain the corresponding wave spectrum and response spectrum. It is well known that the traditional Fourier transform may result in leak of energy, which can introduce larger error to the results.

Recently, Hilbert-Huang transform (HHT) has been developed by Huang et al. (1998) to address mechanics problems. HHT uses two steps to analyze data. The first step is to decompose data in terms of intrinsic characteristic scales into a number of intrinsic mode function (IMF) components by means of empirical mode decomposition (EMD). The second step is to apply the Hilbert transform to the IMF components and obtain the energy distribution on time-frequency, i.e. Hilbert amplitude spectrum or Hilbert spectrum. Further a marginal Hilbert spectrum (MHS) can also be defined. Over the past two decades, HHT has been successfully applied to many water wave problems. Ortega and Smith (2009) performed spectral analysis of storm waves using HHT. Veltcheva and Soares $(2012,2016)$ applied HHT to study characteristics of abnormal waves. Senthilkumar et al. (2015) investigated the characteristics of wave groups in crossing seas using HHT. It is worth noting that the aforementioned studies just focused on the characteristics of waves itself by means of HHT. Whether HHT, especially MHS could be applied to transient waves related seakeeping model tests of a ship to obtain the RAOs has not yet been investigated. Based on abovementioned some issues, the primary aim of this study attempts to apply the MHS analysis to obtain the RAOs of a drilling ship under transient Gaussian wave packets with different focused wave amplitudes. To demonstrate the effectiveness of the approach, corresponding tests based on regular waves were also carried out. The present paper is organized as follows. The Hilbert-Huang transform and its marginal spectrum are introduced in Section 2 following Introduction. Section 3 gives the simulation of transient Gaussian wave packets. The experimental set-up and description are presented in Section 4. The detailed results of the motion, acceleration RAOs based on the transient Gaussian wave packets by MHS and FFT and based on regular waves as well as corresponding discussion are provided in Section 5. Finally, conclusions are drawn based on the present study.

\section{HILBERT-HUANG TRANSFORM AND ITS MARGINAL SPECTRUM}


Hilbert-Huang transform (HHT) was developed as a data analysis method by Huang et al. (1998, 1999). HHT is composed of empirical mode decomposition (EMD) and Hilbert transform. The EMD assumes that an arbitrary data series $x(t)$ can be decomposed into a finite number $n$ of different intrinsic mode functions (IMFs) $C_{i}$ with various time scales so that

$$
x(t)=\sum_{i=1}^{n} C_{i}(t)+r(t)
$$

where $r(t)$ is the residual of the sifting process representing the average tendency of $x(t)$.

Then the analytical signal can be constructed as

$$
Z_{i}(t)=C_{i}(t)+j H\left[C_{i}(t)\right]
$$

where $H\left[C_{i}(t)\right]=\frac{1}{\pi} \int_{-\infty}^{\infty} \frac{C_{i}(t)}{t-t^{\prime}} d t^{\prime}$ namely the Hilbert transform of $C_{i}(t)$.

$$
Z_{i}(t) \text { can also be expressed as }
$$

$Z_{i}(t)=a_{i}(t) e^{j \theta_{i}(t)}$, where the amplitude $a_{i}$, the phase $\theta_{i}$ are calculated by $a_{i}(t)=\sqrt{C_{i}^{2}(t)+H^{2}\left[C_{i}(t)\right]}$ and $\theta_{i}(t)=\arctan \left(\frac{H\left[C_{i}(t)\right]}{C_{i}(t)}\right)$, respectively.

By defining the instantaneous frequency $\omega_{i}$ as $\omega_{i}(t)=\frac{d \theta_{i}(t)}{d t}$ and omitting the residual $r(t)$, then $x(t)$ can be expressed as

$$
x(t)=\operatorname{Re} \sum_{i=1}^{n} a_{i}(t) e^{j \int \omega_{i}(t) d t}
$$

which can be regarded as a generalized form of the Fourier expansion with time variable amplitudes and frequencies. As the amplitude (the energy) and frequency of each component in (3) are functions of time, the final representation of energy is a 3D curve of frequency -time-energy. Thus, the frequency-time distribution of the amplitude is designated as the Hilbert amplitude spectrum $H(\omega, t)$, or simply the Hilbert spectrum (Huang et al., 1999). Then with the Hilbert spectrum, the marginal Hilbert spectrum (MHS) $h(\omega)$ can be defined as

$$
h(\omega)=\int_{0}^{T} H(\omega, t) d t
$$

where $T$ is the total time span of $x(t)$. It can be clearly seen that MHS provides a measure of the total amplitude (energy) distribution from each frequency value. As pointed out by Huang et al. (1999), compared with traditional Fourier spectra, MHS is able to depict more true energy contents. The abovementioned procedure can be implemented by Matlab HHT toolboxes. In order to validate the effectiveness of the Matlab code in this study, the marginal Hilbert spectra of three signals are obtained and compared to the spectra based on FFT. Figs. 1(a) and (b) show the comparisons between the MHS and the FFT spectrum for a monochromatic wave component $x(t)=10 \sin (2 \pi \cdot 0.03 t)$ with a relatively low frequency, and for a monochromatic wave component $x(t)=10 \sin (2 \pi \cdot 0.2 t) \quad$ with a relatively high frequency, respectively. It can be seen that the MHS can not only give correctly the amplitude of the primary waves, but also avoid the leak of energy and have better frequency resolution. Fig. 3 shows the Comparison of the MHS and FFT spectrum of a bichromatic wave group $x(t)=5 \sin (2 \pi \cdot 0.03 t)+10 \sin (2 \pi \cdot 0.2 t)$. It is clearly demonstrated that the MHS shows a much richer energy content in low-frequency range than the corresponding FFT spectrum, which is a characteristic of true waves as pointed out by Huang et al. (1999).
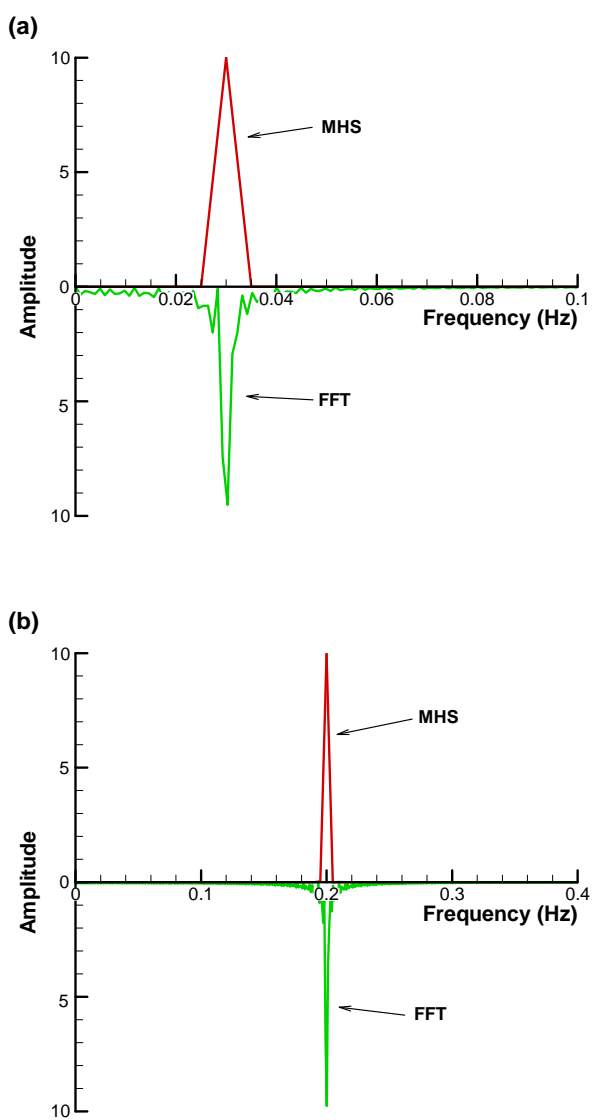

Fig. 1 Comparison of the MHS and FFT spectrum of monochromatic waves: (a) $x(t)=10 \sin (2 \pi \cdot 0.03 t)$; (b) $x(t)=10 \sin (2 \pi \cdot 0.2 t)$ 


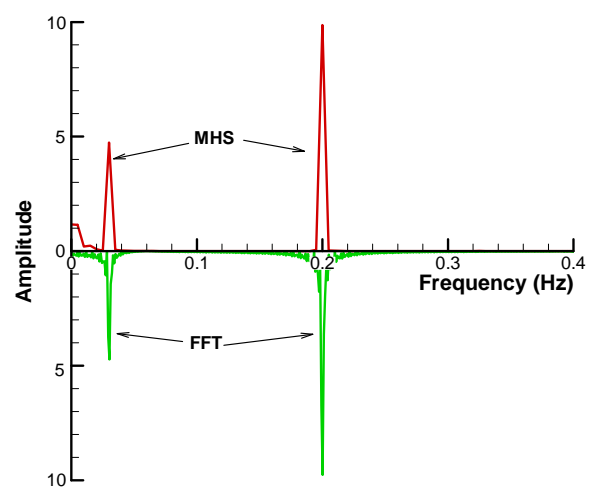

Fig. 2 Comparison of the MHS and FFT spectrum of a bi-chromatic wave group: $x(t)=5 \sin (2 \pi \cdot 0.03 t)+10 \sin (2 \pi \cdot 0.2 t)$

\section{SIMULATION OF TRANSIENT GAUSSIAN PACKETS}

The transient Gaussian wave packets were generated by simulating focused wave trains which satisfy a Gaussian wave spectrum. The Gaussian wave spectrum used in this study can be described as

$$
S(f)=\frac{H_{s}^{2}}{16 \sqrt{2 \pi \sigma^{2}}} e^{-\frac{\left(f-f_{p}\right)^{2}}{2 \sigma^{2}}}
$$

where $H_{s}$ denotes the significant wave height, $f$ the wave frequency $(\mathrm{Hz}), f_{p}$ the spectral peak frequency, $\sigma$ the shape parameter. $H_{s}=0.05 \mathrm{~m}$, $f_{p}=0.714 \mathrm{~Hz}$ and $\sigma=0.16$ are selected in the experiment. The value selected for $f_{p}$ is referred to the natural frequency of the vertical motions (heave and pitch motions) of the ship. The linear superposition theory is frequently applied to simulate transient focused waves by focusing the wave crests or troughs of all the wave components at a specified location and time. The detailed procedure for the simulation can be found in Rapp and Melville (1990).

Tab. 1 shows the parameters of the transient Gaussian wave packets in the tests. The water depth $d=5 \mathrm{~m}$. The number of the component waves $N$ $=100$. $f_{1}$ and $f_{n}$ are the minimum and maximum frequency of the component waves, respectively. $f_{c}$ is the central frequency of the component waves. $k_{c}$ is the wave number corresponding to the central frequency. $A$ is the wave amplitude at the focal point (45 $\mathrm{m}$ far from the wave paddle) based on the assumption of linear superposition theory. $A k_{c}$ is the non-dimensional wave steepness of the wave component with the central frequency and can be used to describe the nonlinearity of transient Gaussian wave packets. As pointed out by Chaplin
(1996), the focused waves based on a wave spectrum with constant steepness start to break when $A k_{c}$ $=0.30$. During the tests, it is found that the breaking inception of transient Gaussian wave packets is still around $A k_{c}=0.30$. Thus, in order to investigate the influence of the nonlinearity of transient Gaussian wave packets, non-breaking cases with different values for $A k_{c}$ are considered in the tests.

Fig. 3 shows the time history of a typical transient Gaussian wave packet measured in the testing (6.5 $\mathrm{m}$ in front of the model ship). It can be seen that the wave profile around the maximum wave crest of the transient Gaussian wave packet near the specified target location exhibits a good symmetry. Fig. 4 shows the comparison between the amplitude spectrum of the measured time history given in Fig. 3 and the target spectrum. It is seen that the agreement between the measured spectrum around the specified location and the target spectrum is satisfactory.

Table 1 Parameters of the transient Gaussian wave packets in the model testing $(d=5 \mathrm{~m})$

\begin{tabular}{cccccc}
\hline Case & $\begin{array}{c}f_{1} \sim f_{\mathrm{n}} \\
(\mathrm{Hz})\end{array}$ & $\begin{array}{c}f_{\mathrm{c}} \\
(\mathrm{Hz})\end{array}$ & $\begin{array}{c}k_{\mathrm{c}}\left(\mathrm{m}^{-}\right. \\
1\end{array}$ & $\begin{array}{c}A \\
(\mathrm{~m})\end{array}$ & $A k_{\mathrm{c}}$ \\
\hline TA005 & $0.25 \sim 1.2$ & 0.725 & 2.115 & 0.050 & $\begin{array}{c}0.10 \\
6\end{array}$ \\
TA008 & $0.25 \sim 1.2$ & 0.725 & 2.115 & 0.080 & $\begin{array}{c}0.16 \\
9\end{array}$ \\
\hline
\end{tabular}

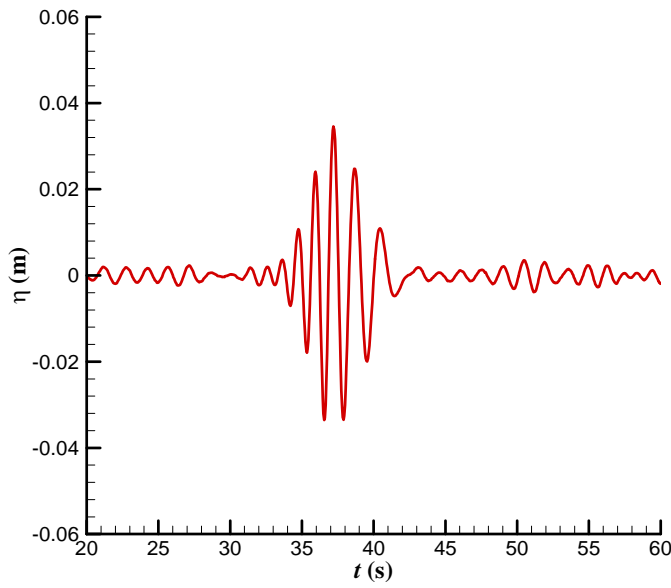

Fig. 3 Time history of a typical transient Gaussian wave packet measured in the testing $(6.5 \mathrm{~m}$ in front of the model ship) 


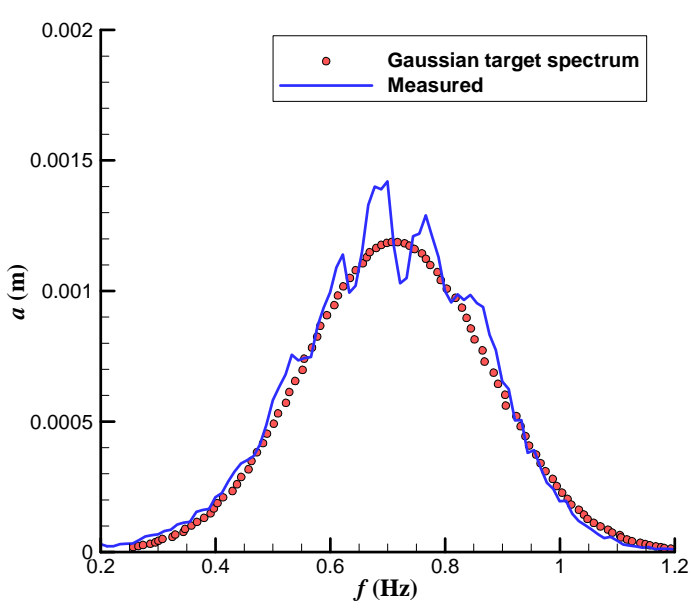

Fig. 4 Comparison between an amplitude spectrum measured in the testing and the correspond target spectrum

\section{EXPERIMENTAL SET-UP AND DESCRIPTION}

The experiment was carried out in the large towing tank at Marine Design and Research Institute of China (MARIC). The length of the tank is $280 \mathrm{~m}$, and the width is $10 \mathrm{~m}$. The water depth in the experiment is $5 \mathrm{~m}$. A flap-type wave maker is equipped at one end of the tank to generate regular or irregular waves, and a slope absorber is equipped at the other end to eliminate the effects of wave reflection. The tested model is a drilling ship. The loading condition corresponds to design draft. Tab. 2 shows the principal particulars of the ship. In order to satisfy geometric similarity, the mass, the centre of gravity (CoG) and the radius of gyration of the model ship were adjusted on a trimming table. In order to constrain the slow drift motion of the model in the tests and avoid the influence on the primary motions of the model in the tests, the model ship was moored above water to the towing carriage by 4 horizontal mooring lines composed of short springs and thin steel wires. The stiffness of the springs was selected appropriately to ensure the surge and sway natural period of the mooring system far from the primary wave period range in the tests. Each two mooring lines with an intersection angle of 90 deg were attached to the ship bow and stern near the height of the CoG of the model, respectively. Fig. 5 shows the configuration of the mooring system in the tank. Fig. 6 shows a snapshot of the ship model in waves.

A non-contact optical motion capture system was employed to measure the 6 degrees of freedom (DOF) motions at the CoG of the ship. The quadratic differential of the time history of the heave motion displacement was used to obtain the heave acceleration RAOs. The sampling frequency in the test is $20 \mathrm{~Hz}$. Before the sea-keeping model tests, inclining test and free decay test in still water were carried out to ensure the correctness of the adjustment of the CoG and the radius of gyration. In order to validate the experimental results based on transient waves, the model tests based on a series of regular waves with constant wave height were also carried out.

Table 2 Main particulars of the drilling ship

\begin{tabular}{cccc}
\hline Item & Symbol Unit Model \\
\hline Overall length & $L_{\mathrm{oa}}$ & $\mathrm{m}$ & 4.4950 \\
Length between perpendiculars & $L_{\mathrm{pp}}$ & $\mathrm{m}$ & 4.2000 \\
Breadth & $B$ & $\mathrm{~m}$ & 0.8000 \\
Depth & $D$ & $\mathrm{~m}$ & 0.3875 \\
Design draft & $d$ & $\mathrm{~m}$ & 0.2300 \\
Displacement & $\Delta$ & $\mathrm{t}$ & 0.6298 \\
$\begin{array}{c}\text { Longitudinal center of gravity } \\
\text { (from after perpendicular) }\end{array}$ & $L C G$ & $\mathrm{~m}$ & 2.0430 \\
Vertical center of gravity & $V C G$ & $\mathrm{~m}$ & 0.3258 \\
(above keel) & & $\mathrm{m}$ & 0.3311 \\
Radius of gyration for roll & $R_{\mathrm{xx}}$ & $\mathrm{m}$ & 1.1561 \\
Radius of gyration for pitch & $R_{\mathrm{yy}}$ & $\mathrm{m}$ & \\
\hline
\end{tabular}

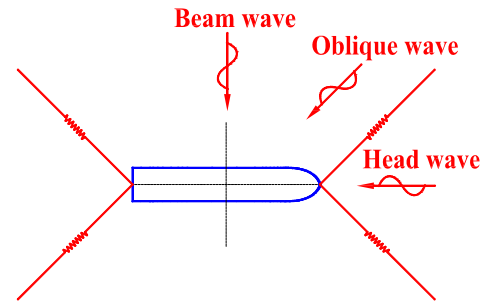

Fig. 5 Configuration of the mooring system in the tank

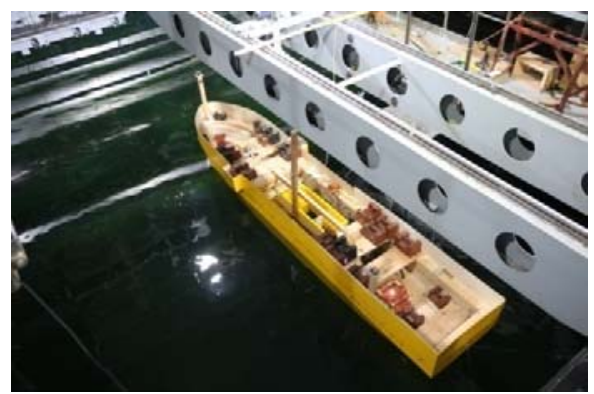

Fig. 6 A snapshot of the ship model in waves

\section{RESULTS AND DISCUSSION}

The experimental results include the measurements of free decay tests of heave, roll and pitch motion of the ship in still water and the primary motion, acceleration RAOs of the drilling ship in head waves, bow quartering waves and beam waves, respectively. In order to obtain those RAOs based on transient waves, the corresponding response spectrum and wave spectrum by FFT and MHS were firstly obtained, respectively. By means of the ratio between 
the response spectrum and wave spectrum, it is easy to obtain the corresponding RAO curve after appropriate smoothing processing. All the experimental results are transformed into full scale results.

\section{Free decay tests in still water}

Figs. 7-9 show the free decay curves of the heave, roll and pitch motion of the ship in still water. The non-dimensional damping coefficient $\mu$ can be calculated as

$$
\mu=\frac{1}{\pi} \ln \left|\frac{\phi_{\mathrm{An}}}{\phi_{\mathrm{A} n+1}}\right|,
$$

where $\phi_{\mathrm{A} n}>\phi_{\mathrm{A} n+1}, \phi_{\mathrm{A} n}$ and $\phi_{\mathrm{A} n+1}$ represent the $n$th and $(n+1)$ th peak values or trough values of decay curves, respectively.

Tab. 3 shows the natural period and nondimensional damping coefficient $\mu$ of the corresponding motion by means of the decay curves. It can be seen that the natural periods lie in a common wave period range (5-30 s in full scale).

Table 3 Results of free decay tests in still water

\begin{tabular}{|c|c|c|c|c|c|}
\hline \multicolumn{6}{|c|}{ water } \\
\hline & eave & & Roll & & Pitch \\
\hline $\begin{array}{c}\text { Peri } \\
\text { od } \\
\text { (s) }\end{array}$ & $\begin{array}{l}\text { Non- } \\
\text { dimensi } \\
\text { onal } \\
\text { Dampin } \\
\text { g } \\
\text { coeffici } \\
\text { ent } \\
\end{array}$ & $\begin{array}{c}\text { Peri } \\
\text { od } \\
\text { (s) }\end{array}$ & $\begin{array}{l}\text { Non- } \\
\text { dimensi } \\
\text { onal } \\
\text { Dampin } \\
\text { g } \\
\text { coeffici } \\
\text { ent } \\
\end{array}$ & $\begin{array}{c}\text { Peri } \\
\text { od } \\
\text { (s) }\end{array}$ & $\begin{array}{c}\text { Non- } \\
\text { dimensi } \\
\text { onal } \\
\text { Dampin } \\
\text { g } \\
\text { coeffici } \\
\text { ent } \\
\end{array}$ \\
\hline 8.6 & 0.236 & 21.3 & 0.021 & 8.4 & 0.187 \\
\hline
\end{tabular}

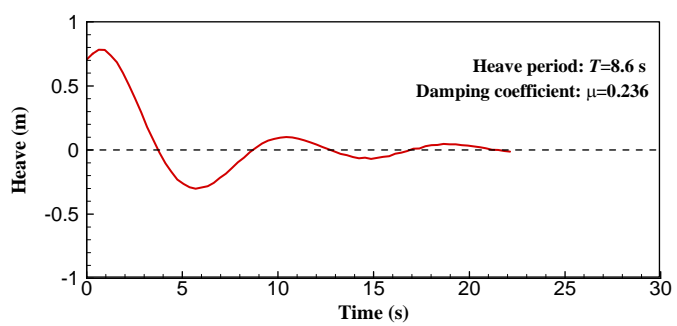

Fig. 7 Free decay curve of the heave motion

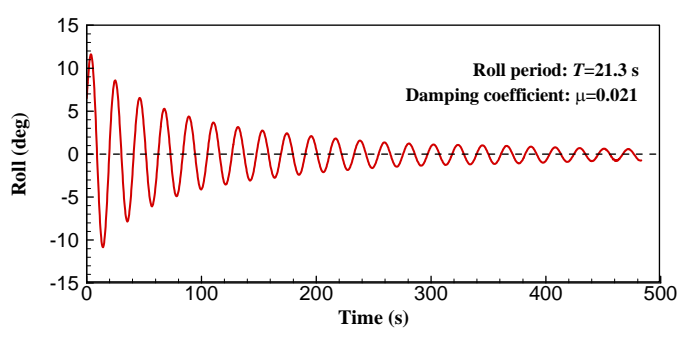

Fig. 8 Free decay curve of the roll motion

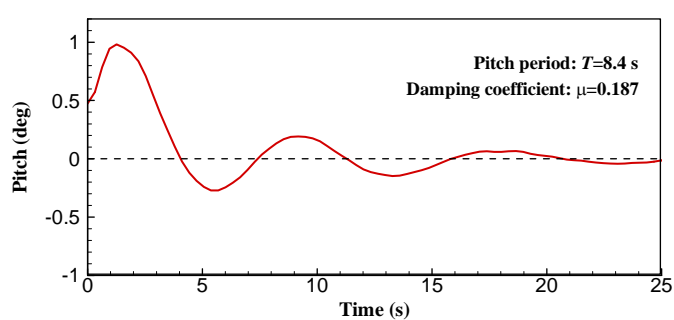

Fig. 9 Free decay curve of the pitch motion

\section{Motion RAOs}

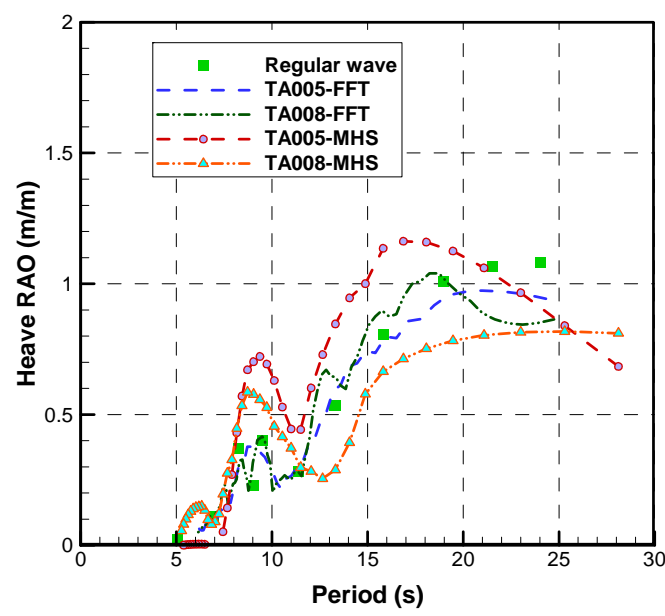

Fig. 10 Heave RAOs in head waves

Figs. 10-12 show the heave RAOs of the ship in head waves, bow quartering waves and beam waves, respectively. It can be seen in the three figures that as wave period increases, the heave RAOs based on regular waves increase and approach gradually a relatively stable value $(1 \mathrm{~m} / \mathrm{m})$.

As can be seen in Fig. 10, the heave RAOs in head waves based on the two transient Gaussian wave packets (Cases TA005 and TA008) by FFT ranging from 5 to $20 \mathrm{~s}$ are in good agreement with those based on regular waves. Over the range from 20 to $25 \mathrm{~s}$, the discrepancies increase as the nonlinearity of the Gaussian wave packet increases. This is probably due to that the energy of the wave packets over the range from 20 to $25 \mathrm{~s}$ is relatively less resulting in relatively large error. It can also be seen that the heave RAOs based on the two transient Gaussian wave packets by MHS have relatively prominent differences with those based on regular waves. However, the tendency of the heave RAOs by MHS compared to that based on regular waves appears to be acceptable. It is worth noting that the heave RAOs by MHS appear to be more sensitive to the focused wave amplitude of the transient wave packets. 


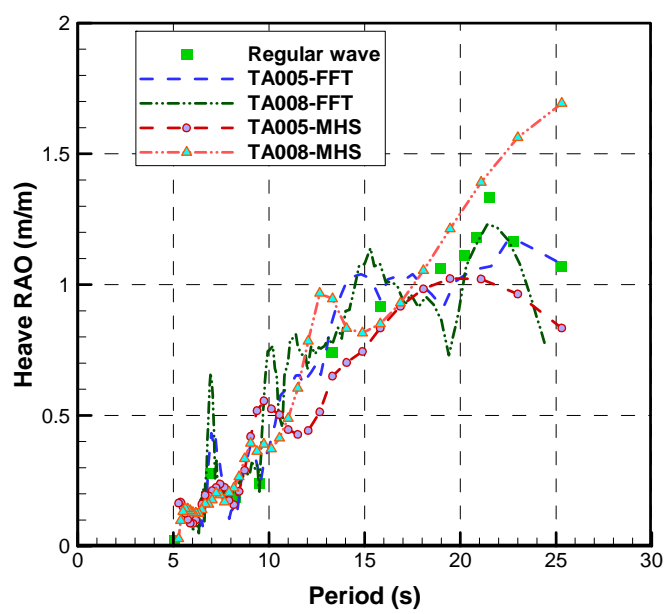

Fig. 11 Heave RAOs in bow quartering waves

As shown in Fig. 11, the heave RAOs of the ship in bow quartering waves based on the two transient Gaussian wave packets by both FFT and MHS ranging from 5 to $20 \mathrm{~s}$ appear to agree reasonably well with those based on regular waves. The relatively prominent differences still arise over the range from 20 to $25 \mathrm{~s}$. The peaks around $7 \mathrm{~s}$ of the heave RAOs may be due to the piston motions of the fluid within the moon pool. It is noticed that a small crest of the heave RAOs based on regular waves arises around the wave period of $21 \mathrm{~s}$ probably due to the influence of the occurrence of the resonant rolling motion of the ship at the wave period of $21 \mathrm{~s}$.

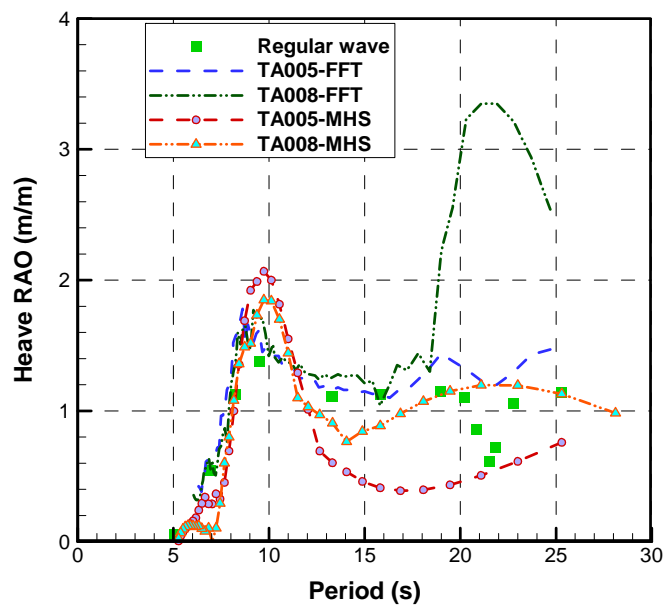

Fig. 12 Heave RAOs in beam waves

As can be seen in Fig. 12, the heave RAOs of the ship in beam waves based on the two transient Gaussian wave packets by FFT ranging from 5 to 17 $\mathrm{s}$ are in good agreement with those based on regular waves. Over the range from 17 to $25 \mathrm{~s}$, the tendency of the heave RAOs based on Case TA005-FFT appears to be similar to that based on regular waves, while the heave RAOs based on Case TA008-FFT exhibit quite pronounced discrepancies with those based on regular waves. It is also seen that the tendency of the heave RAOs based on Case TA008MHS is in better agreement with that based on regular waves, while the tendency based on Case TA005-MHS holds relatively large differences with that based on regular waves. This indicates that the nonlinearity of the transient wave packets may influence significantly the heave RAOs of the ship in beam waves, especially over the wave period range where the energy content within the wave packets is relatively less and the motions are relatively severe. It is also pointed out that for the RAOs in beam waves based on regular waves, a small trough around $21 \mathrm{~s}$ appears probably due to the influences of significant resonant rolling on the heave motion.

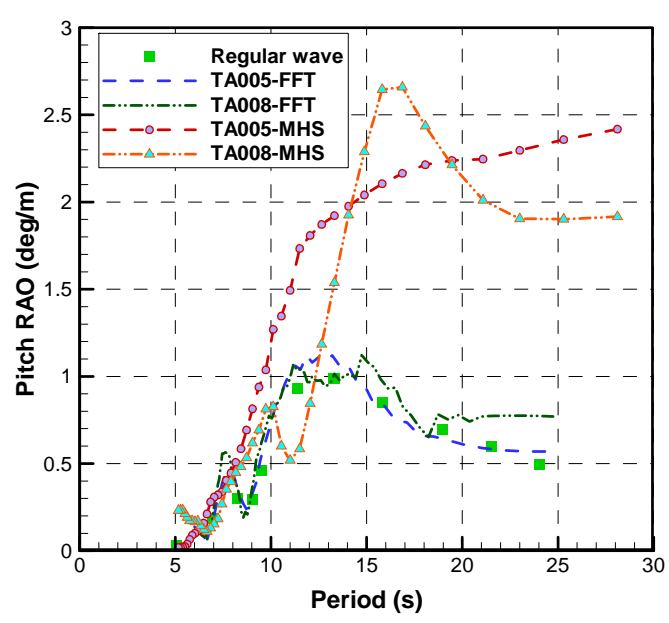

Fig. 13 Pitch RAOs in head waves

Fig. 13 shows the pitch RAOs of the ship in head waves. It is seen that the pitch RAOs based on regular waves exhibit evident wave frequency characteristic. The peak value period of the pitch RAO of the ship in head waves is approximately $12 \mathrm{~s}$ corresponding to wavelength/ship length $=1.3$. A small peak appears around the natural pitch period (8.4 s). This indicates that the most significant pitch motion of the drilling ship in head waves does not depend on the resonant wave period, but depend on the ratio between the wavelength and ship length, which is similar to the pitch motion characteristics of common ships, i.e. the most significant pitch motion occurs when the ratio between wavelength and ship length is around 1. As can be seen in Figure 13, the pitch RAOs based on Case TA005-FFT are in good agreement with those based on regular waves, and can capture effectively the peaks of the pitch RAOs. As for Case TA008-FFT, the discrepancies with those based on regular waves increase especially over the range from 20 to 25 s mainly due to the effect of the increased nonlinearity in Case TA008-FFT. Moreover, it can also be seen that the pitch RAOs based on Cases TA005-MHS and TA008-MHS have 
evident discrepancies with those based on regular waves over the range from 10 to $25 \mathrm{~s}$. This is presumably due to that the MHS method itself may generate larger errors in this case resulting in irrational pitch RAOs in head waves.

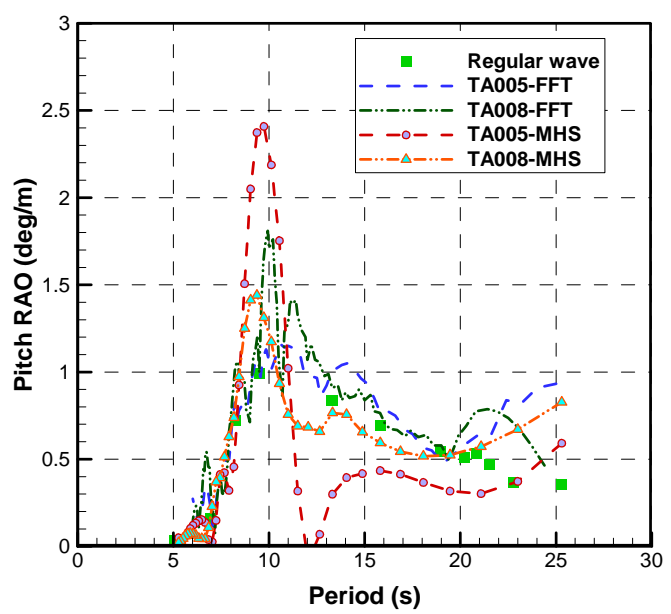

Fig. 14 Pitch RAOs in bow quartering waves

Fig. 14 shows the pitch RAOs of the ship in bow quartering waves. The peak value period of the pitch RAOs based on regular waves is approximately $8.5 \mathrm{~s}$, which agrees well with the natural pitch period obtained by decay test $(8.4 \mathrm{~s})$. This indicates that the pitch motion of the drilling ship in bow quartering waves have maximum amplitude when the resonant motion occurs. Moreover, it can be seen that the RAOs based on TA005-FFT are in acceptable agreement with those based on regular waves. As the focused wave amplitude increases, the discrepancies between the results based on FFT and the results based on regular waves become more evident. It is noticed that the RAOs obtained by TA008-MHS appear to agree better with those based on regular waves compared to those obtained by TA005-MHS.

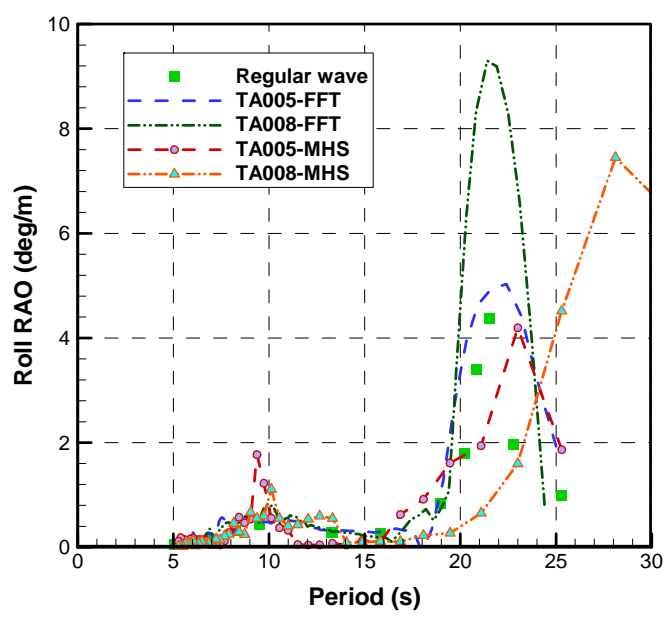

Fig. 15 Roll RAOs in bow quartering waves

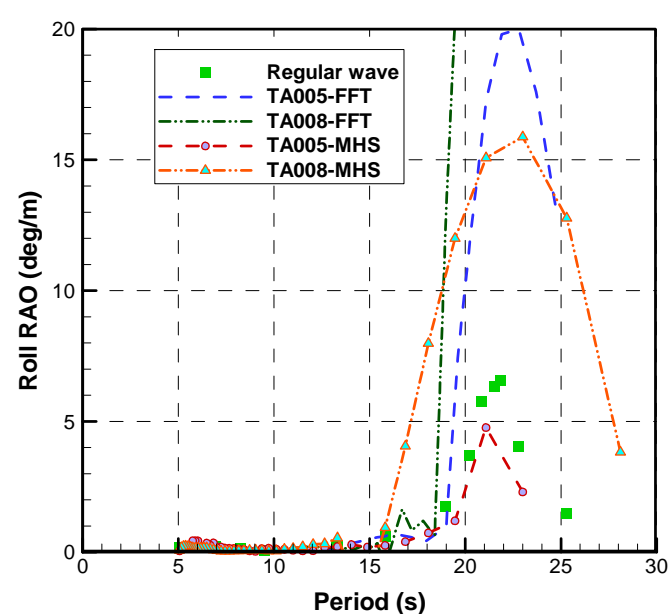

Fig. 16 Roll RAOs in beam waves

Fig. 15 shows the roll RAOs of the drilling ship in bow quartering waves. As can be seen in Fig.15, the peak value of the roll RAOs based on regular waves reaches $4.5 \mathrm{deg} / \mathrm{m}$ and the peak value period is around $21 \mathrm{~s}$, which is in good agreement with that obtained by decay test (21.3 s). Moreover, for the transient wave packet with smaller focused wave amplitude, the roll RAOs by FFT and MHS have smaller differences with those based on regular waves. As the focused amplitude increases, the roll RAOs by both FFT and MHS have pronounced discrepancies with those based on regular waves. Fig. 16 shows the roll RAOs of the drilling ship in beam waves. It can be seen that the peak value period of the RAOs based on regular waves is still around $21 \mathrm{~s}$. It is worth noting that the RAOs based on Cases TA005 and TA008 by FFT have quite significant discrepancies with those based on regular waves over the range from $15 \mathrm{~s}$ to $25 \mathrm{~s}$, while the RAOs based on Cases TA005 and TA008 by MHS appear to provide better agreement with those based on regular waves, especially the transient wave with smaller focused wave amplitude (Case TA005-MHS). This indicates that the MHS method may be more reliable to predict the roll RAOs based on a transient wave packet with adequate focused wave amplitude.

\section{Acceleration RAOs}

Fig. 17 shows the heave acceleration RAOs at the CoG of the ship in head waves. It can be seen that the heave acceleration RAOs at the CoG based on Cases TA005 and TA008 by FFT exhibit a relatively better agreement with those based on regular waves, while the heave acceleration RAOs based on Cases TA005 and TA008 by MHS appear to provide merely a similar tendency to that based on regular waves. As the heave acceleration RAOs are obtained by the quadratic differential of the time history of the heave motion displacement, the relatively large differences 
between the heave acceleration RAOs by MHS and by regular waves result from the relatively larger differences between the heave RAOs by MHS and by regular waves as shown in Fig. 10.

Figs. 18 and 19 show the heave acceleration RAOs at the CoG of the ship in bow quartering waves and beam waves, respectively. It can be seen that the RAOs based on Cases TA005-FFT and TA005-MHS demonstrate a better agreement to that based on regular waves. As the focused wave amplitude increases, the discrepancies enlarge correspondingly. Similar to the motion RAOs, the nonlinearity of the wave packets as well as the relatively less energy distribution around low frequency may result in significant errors.

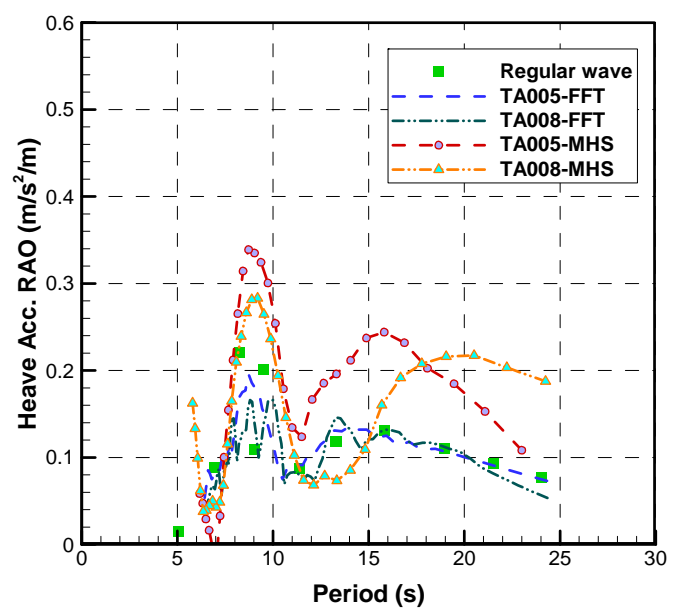

Fig. 17 Heave acceleration RAOs at the CoG of the ship in head waves

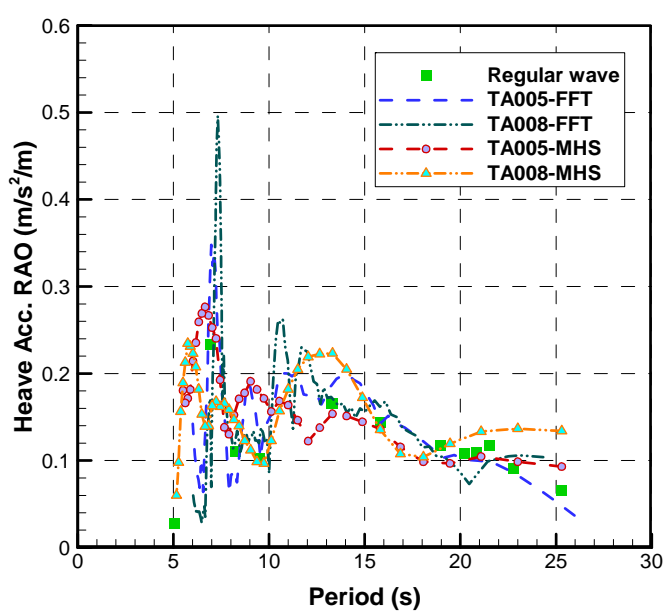

Fig. 18 Heave acceleration RAOs at the CoG of the ship in bow quartering waves

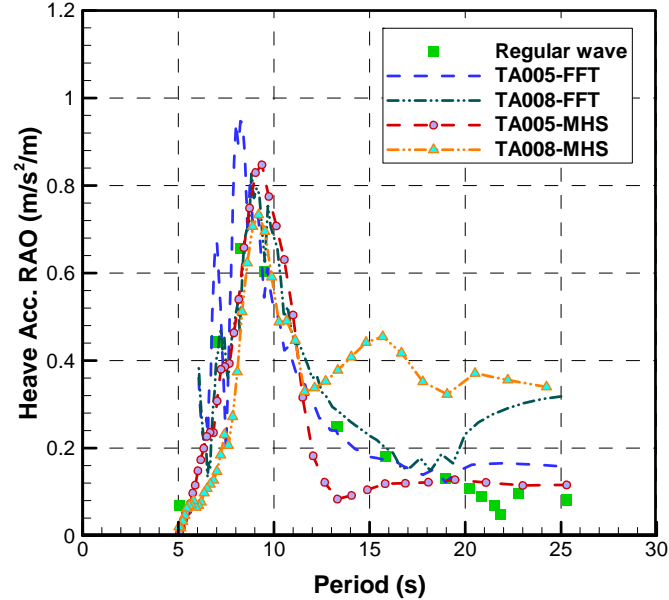

Fig. 19 Heave acceleration RAOs at the CoG of the ship in beam waves

\section{CONCLUSIONS}

In this study, the transient Gaussian wave packets with different focused wave amplitudes were generated in a large towing tank to conduct seakeeping model tests of a drilling ship under the condition of head waves, oblique waves and beam waves, respectively. The marginal Hilbert spectrum in the framework of the Hilbert-Huang transform and the Fourier spectrum are employed to obtain the motion, acceleration RAOs of the drilling ship. In order to validate the RAO results based on transient Gaussian wave packets, the corresponding regular wave tests were also carried out. The main conclusions can be drawn as follows.

In comparison to FFT, the transient Gaussian wave packets with smaller focused wave amplitude $\left(A k_{\mathrm{c}}=0.106\right)$ combined with MHS can give more reasonable roll RAO results of the ship in both bow quartering and beam waves, but irrational pitch RAO results of the ship in head waves. The post-processing based on MHS may be further studied in detail.

The spectrum peak period of the transient Gaussian wave packets used in this study is near to the natural period of heave and pitch motions of the ship, but far from the natural period of roll. This may be the reason why the RAO results around the natural period of roll based on transient wave packets exhibit relatively significant differences with those based on regular waves. Although MHS can improve the roll RAO results to some extent, the transient Gaussian wave packets with spectrum peak period near to the natural period of roll of ships should be applied to obtain better results of roll RAOs in future studies.

Huang et al. (1999) pointed out that marginal Hilbert spectra should not be used for any nonstationary data. However, in this study, it appears that the marginal Hilbert spectra of the transient Gaussian wave packets which are a typical kind of non- 
stationary waves can be applied to obtain satisfactory results of motion and acceleration RAOs of the drilling ship over the primary wave period range except the pitch RAOs in head waves. It is worth noting that MHS can effectively improve the roll RAOs results compared with FFT based on the employed transient Gaussian wave packets.

This paper attempts to demonstrate an alternative approach to obtain RAOs of a ship under transient waves, and the study presented is expected that the MHS approach can play a vital role in future sea-keeping model tests of ships.

\section{REFERENCES}

[1] Davis, M C. and Zarnick, E E. Testing ship models in transient waves[C], Proceedings of the $5^{\text {th }}$ Symposium on Naval Hydrodynamics, ONR, Bergen, Norway, 1964.

[2] Takezawa and Hirayama. Advanced experiment technique for testing ship models in transient water waves[C]. Proceedings of the $11^{\text {th }}$ Symposium on Naval Hydrodynamics, ONR, University College, London, 1976.

[3] Clauss G F and Bergmann J. Gaussian wave packets - a new approach to sea-keeping tests of ocean structures[J]. Applied Ocean Research, 1986, 8(4): 190-206.

[4] Zhao W, Wolgamot H A, Taylor P H and Taylor R E. Gap resonance and higher harmonics driven by focused transient wave groups [J]. Journal of Fluid Mechanics, 2017, 812: 905-939.

[5] Tromans, P. S., Anaturk, A. R. and Hagemeijer, P. A new model for the kinematics of large ocean waves - application as a design wave[C]. Proceedings of the First International Offshore and Polar Engineering Conference, Edinburgh, UK, 1991.
[6] Grigoropoulos G J, Florios N S and Loukakis T. A. Transient waves for ship and floating structure testing[J]. Applied Ocean Research, 1994, 16: 71-85.

[7] Reilhac P, Bonnefoy F, Rousset J M and Ferrant P. Improved transient water wave technique for the experimental estimation of ship responses [J]. Journal of Fluids and Structures, 2011, 27: 456-466.

[8] Rapp R J and Melville W K. Laboratory measurements of deep water breaking waves[J]. Phil. Trans. R. Soc. Lond. A, 1990, 331: 735-800.

[9] Chaplin J R. On frequency-focusing unidirectional waves[J]. International Journal of Offshore and Polar Engineering, 1996, 6: 131-137.

[10] Huang N E, Shen Z, Long SR, Wu ML, Shih $\mathrm{HH}$, et al. The empirical mode decomposition and Hilbert spectrum for nonlinear and nonstationary time series analysis. Proc. R. Soc. London Ser: A, 1998, 454:903-95

[11] Ortega J and Smith G. Hilbert_Huang transform analysis of storm waves. Applied Ocean Research, 009,31:212-219.

[12] Veltcheva AD and Soares CG. Analysis of abnormal wave groups in Hurricane Camille by the Hilbert Huang Transform method. Ocean engineering, 2012, 42:102-111.

[13] Senthilkumar R, Romolo A, Fiamma V et al. Analysis of Wave Groups in Crossing Seas Using Hilbert Huang Transformation. Procedia Engineering, 2015,116: 1042-1049.

[14] Veltcheva AD and Soares CG. Nonlinearity of abnormal waves by the Hilbert-Huang Transform method. Ocean engineering, 2016, 115:30-38.

[15] Huang NE, Shen Z and Long SR. A new view of nonlinear water waves: The Hilbert Spectrum. Annu. Rev. Fluid. Mech., 1999, 31:417-57. 